\title{
Judicialização da educação: regime de colaboração e rede de proteção social da criança e do adolescente
}

\author{
Rafaela Reis Azevedo de Oliveira* \\ \& Beatriz de Basto Teixeira**
}

Resumo: Este artigo apresenta resultados de tese de doutorado que analisou as ações da Promotoria da Infância e Juventude, e dos Conselhos Tutelares para a garantia do acesso à educação infantil no município de Juiz de Fora (MG), que tramitaram entre 2009 e 2014. A pesquisa foi realizada por meio de revisão bibliográfica, análise documental e entrevistas semiestruturadas. Como resultados, aponta-se a dificuldade do município em garantir o acesso à educação infantil, sobretudo a subetapa de creches, e o cumprimento de metas estipuladas em política nacional de educação; a inoperância da rede de proteção social da criança e do adolescente; e o movimento de (des)judicialização da educação, haja vista a entrada em cena de um outro ator para a exigibilidade do direito da criança: o Poder Legislativo.

Palavras-chave: Judicialização da educação. Regime de colaboração. Ministério Público. Conselhos Tutelares. Poder Legislativo.

\section{Judicialization of education: collaboration scheme and child and adolescent social protection network}

Abstract: This article presents the results from a doctoral dissertation that analyzed the actions taken by the Office for the Protection of Children and Youth and the Child Protective Services, from 2009 to 2013, in order to guarantee access to Early childhood education in the city of Juiz de Fora, Minas Gerais. The research was conducted by means of bibliographical review, documental analyses and semi-structured interview. As examples of brief results, it is pointed out the city's difficulty in securing access to Early childhood education, especially to nursery schools, and fulfilling the goals established in national education guidelines; the ineffectiveness of the children and youth's social protection network; and the movement of (de)Judicialization of education, considering the participation of another actor for demanding children's right: the legislative power.

Keywords: Judicialization of education. Collaboration scheme. Public Prosecutor's Office. Child Protective Services. Legislative Power.

A

demanda judicial pela educação é uma ação bastante recorrente nos dias atuais. Pesquisas acadêmicas (Casagrande, 2008; Silveira, 2008; Vieira, 2008; Cury et alii, 2009) e exploratórias nos endereços eletrônicos dos Mi-
Recebido: 25.09.17

Aprovado: 23.08 .18
* Rafaela Reis

Azevedo de Oliveira

é graduada em ciências sociais, com mestrado e doutorado em educação. Atuou como professora de sociologia no Instituto Federal de Rio de Janeiro e atualmente é professora do departamento de Educação da Universidade Federal de Juiz de Fora (UFJF), Juiz de Fora, Minas Gerais, Brasil, na área de sociologia. <rafareis2001@ yahoo.com.br>.

\footnotetext{
** Beatriz de Basto Teixeira é graduada em ciências sociais, com mestrado e doutorado em educação. Professora titular aposentada do Departamento de Ciências Sociais da Universidade Federal de Juiz de Fora (UFJF), Juiz de Fora, Minas Gerais, Brasil, e dos Programas de Pós-Graduação em Educação e Profissional em Gestão e Avaliação da Educação Pública da UFJF. Orcid: 0000-00016864-644. $<$ bbtbia@gmail. com>.
} 
nistérios Públicos Estaduais, do Superior Tribunal de Justiça ou mesmo em jornais e revistas, permitem identificar uma crescente demanda dessa natureza. Isso decorre da ampliação de direitos dos indivíduos e de seus mecanismos de exigibilidade e a ocorrência da inconstitucionalidade do não atendimento ao direito à educação. De fato, verificamos, na esfera judicial, demandas por acesso à escola pública, por transporte público para crianças e adolescentes, por garantia de material didático, por merenda escolar e até por questões bastante específicas, como o acompanhamento de aluno por professor habilitado em Língua Brasileira de Sinais (Libras).

Ao observar a primeira etapa da Educação Básica - a Educação Infantil (EI), de zero aos 5 anos -, constata-se, de maneira geral, um crescimento de ações judiciais e de demandas aos órgãos municipais oriundas dos órgãos de defesa da criança e do adolescente, como são os Conselhos Tutelares (CT) e as Promotorias e Defensorias Públicas da Infância e Juventude. A demanda nessa etapa se caracteriza basicamente pela garantia de acesso, sobretudo em sua primeira subetapa, às creches, que atendem crianças de 0 a 3 anos (Correa, 2010; Mattos, 2014).

A essa demanda - que não é exclusiva de Juiz de Fora, mas observada em todo o território nacional - podem ser atribuídas algumas causas como a entrada da mulher no mercado de trabalho; a necessidade de guarda para as crianças; o fato de a Educação Infantil ter se tornado a primeira etapa da Educação Básica; de as creches terem saído do âmbito assistencial e passado ao educacional; o ativismo judicial, haja vista os próprios dispositivos legais que o fazem defensor dos direitos sociais, quando se deparam com a inconstitucionalidade; a focalização de políticas educacionais, com a vinculação orçamentária para a etapa do Ensino Fundamental; a ampliação do tempo de escolaridade obrigatória, incluindo a etapa pré-escolar e, ainda, o estabelecimento de metas de atendimento da Educação Infantil pelo Plano Nacional de Educação (PNE) (Kramer, 2006; Kulhmann Jr., 2004; Rosemberg, 1999).

Ao considerar as causas acima destacadas, nosso estudo procurou responder à seguinte questão: a atuação de Promotorias da Infância e Juventude, bem como dos Conselhos Tutelares, tem contribuído para a efetividade do direito ao acesso à Educação Infantil, quando ele se encontra lesado pelo poder público? Com o objetivo de ajudar a responder a esta questão, este texto está organizado da seguinte forma: em um primeiro momento, constrói-se um panorama da Educação Infantil no Brasil; posteriormente, destaca o regime de colaboração, como mecanismo da Federação para a realização de políticas públicas educacionais; em um terceiro momento, apresenta-se a judicialização como mecanismo de garantia de direitos 
sociais, com atenção especial ao direito à educação; e, por fim, discute-se o processo de judicialização da Educação Infantil, tendo como base a pesquisa realizada no município mineiro já mencionado.

\section{Educação Infantil: \\ breve balanço das políticas públicas no Brasil}

Há mais de uma década, Fúlvia Rosemberg (2002), ao discutir a atuação de organismos multilaterais e do Estado brasileiro nas políticas públicas para a Educação Infantil, caricaturou a primeira etapa da Educação Básica com o título de "Rainha da sucata". Esse título teve como fundamento os investimentos ainda precários realizados pelos países em desenvolvimento nessa etapa de ensino. Além de "denunciar" esse baixo investimento, a autora destacava que, graças a isso, os espaços que recebiam crianças eram, em sua maioria, inadequados; os profissionais que atuavam não eram devidamente qualificados; e os materiais pedagógicos também eram bastante precários.

A Educação Infantil, apesar de ainda apresentar os problemas destacados por Rosemberg, passou por grandes avanços a partir da promulgação da Constituição Federal de 1988, que lançou um novo olhar sobre a criança pequena. $O$ atendimento à infância, que estivera historicamente atrelado a uma concepção de assistência - ou até mesmo compensatória - é colocado na dimensão de um direito, o educacional. Conforme destaca Kramer, a criança, com a promulgação da Constituição, "deixa de ser alguém que não é (pelo menos nas discussões acadêmicas) e passa à condição de cidadã (pelo menos na letra da lei)" (Kramer, 1996: 17).

Dentre os avanços decorridos da Constituição Federal de 1988, destaca-se a organização de um quadro normativo abrangente, que se iniciou com a definição da Educação Infantil como a primeira etapa da Educação Básica na Lei de Diretrizes e Bases da Educação Nacional de 1996. Anos depois, em 2009, com a disposição da Emenda Constitucional n. ㅇ 59, a etapa de escolarização obrigatória foi ampliada, passando a abranger dos 4 a 17 anos, ou seja, tornando a segunda subetapa da Educação Infantil, a pré-escola, como obrigatória e de direito público subjetivo. Na sequência, em 2013, foi implementada a Lei n. 12.796, que tornou a matrícula das crianças de 4 e 5 anos obrigatória por parte dos pais.

A Educação Infantil também figurou nas políticas educacionais mais recentes, como no Plano Nacional de Educação. Tanto na edição 2001-2010, como na edição 2014-2024, houve o estabelecimento de metas de atendimento para suas duas su- 
betapas - creche e pré-escola. Identificou-se que, na execução do Plano Nacional de Educação (2001-2010), estavam previstos percentuais de atendimento tanto para a primeira como para a segunda subetapa, que não foram alcançados pela maioria dos municípios. No Plano Nacional de Educação (2001-2010) a meta de acesso era ampliar a oferta de Educação Infantil de forma que $50 \%$ da população de até 3 anos e $80 \%$ das crianças de 4 a 5 anos fossem atendidas até o final da década. Ao final de 2010, a meta para a pré-escola havia sido conquistada, visto que $80 \%$ das crianças estavam matriculadas, contudo, nas creches, apenas $18 \%$. Assim, no Plano Nacional de Educação 2014-2024, redefiniram-se as metas, sendo que para crianças de 4 e 5 anos era universalizar o atendimento no ano de 2016 e atender $50 \%$ das crianças de 0 a 3 anos de idade até o ano final de vigência do Plano, em 2024.

Sabe-se que o atendimento à pré-escola se encontra em vias de universalização em boa parte dos municípios brasileiros, já que, desde a execução do Plano Nacional de Educação 2001-2010, tem havido esforços no sentido de ampliar a rede de atendimento. Ocorre, todavia, que o grande gargalo da Educação Infantil tem sido a subetapa de creches. Além de ser a aquela com maior déficit de atendimento em todo o país, é a que demanda maiores recursos financeiros, haja vista a necessidade de uma infraestrutura adequada ao atendimento de bebês e a demanda por atendimento em tempo integral pela maior parte das famílias (Pinto, 2009).

Outro aspecto a ser destacado foi a inclusão da Educação Infantil no Fundo de Manutenção e Desenvolvimento da Educação Básica e de Valorização dos Profissionais da Educação, o Fundeb. A inclusão da etapa no Fundeb é um ganho significativo, tendo em vista que os investimentos na Educação Infantil foram sempre residuais, sobretudo durante a vigência do Fundef, que era destinado à única etapa então obrigatória, o Ensino Fundamental. Muitos municípios admitiram - como no caso de Juiz de Fora (MG) - que a grande demanda de acesso à Educação Infantil e o não investimento público nessa etapa se deram em função do que estava definido como prioridade de atendimento naquele momento.

No que compete à formação de profissionais que atuarão na Educação Infantil, a legislação previu a formação em nível superior (licenciatura em pedagogia), sendo admitida a formação em nível médio, na modalidade Normal. A Lei de Diretrizes e Bases da Educação Brasileira (LDB), que trouxe esse dispositivo, ao fazer isso, equiparou a formação dos profissionais da Educação Infantil à dos profissionais dos primeiros anos do Ensino Fundamental, compreendendo, desse modo, sua inclusão em um plano de carreira, a disponibilidade de formação continuada oferecida pelos 
municípios e a definição de um piso salarial. A lei previu, ainda, a valorização desses profissionais em termos de seleção e contratação.

Por fim, destacam-se dentre os avanços para a Educação Infantil, a definição das Diretrizes Curriculares Nacionais e Referenciais Curriculares Nacionais para a Educação Infantil. A definição dessas Diretrizes e Referenciais Curriculares coloca, em definitivo, a Educação Infantil sob a guarda da Educação, a partir da definição de objetivos específicos para cada subetapa. Embora não seja o foco do trabalho, ressalta-se que esses componentes curriculares definidos não vieram isentos de um debate acalorado em torno do tema. O grande dilema é pensar a concepção de ensino que está sendo oferecido nas instituições de Educação Infantil. Assim sendo, ela estaria a serviço da preparação da criança para o Ensino Fundamental, englobando mesmo o próprio formato de escolarização presente na etapa de ensino seguinte ou deveria se desenvolver em meio às suas próprias peculiaridades - assim como os documentos oficiais destacam - sob as dimensões do cuidar e do educar?

Historicamente, a Educação Infantil teve um caráter assistencialista, pois se destinava às crianças em situação de vulnerabilidade social ou era um lugar de guarda do filho da mãe trabalhadora (Kulhmann Jr., 2004). Hoje, dada a insuficiência de vagas na rede pública de ensino, os municípios ainda têm focalizado o atendimento a crianças em condições socioeconômicas mais desfavorecidas, adotando, como é o caso de Juiz de Fora, critérios de vulnerabilidade estabelecidos pelo Sistema Único de Assistência Social. De todo modo, entende-se que, apesar da necessidade de focalizar o atendimento a partir de critérios socioeconômicos, os avanços apresentados ao longo desta seção dão condições de afirmar que houve importantes passos na direção de superar, em definitivo, a visão assistencialista da Educação Infantil. Conforme nossa legislação, a Educação Infantil visa ao desenvolvimento integral da população de 0 a 5 anos de idade; é direito das crianças, e sua oferta é dever do Estado.

Ao que tudo indica, a Educação Infantil passou por seu próprio processo de reforma educacional (Cerisara, 2002), no qual foram definidas suas formas de financiamento, suas diretrizes curriculares e a formação mínima dos profissionais que devem nela atuar. Porém, ela não está isenta de desafios para que haja a oferta universalizada e de qualidade para as crianças de 0 a 5 anos. Um desses desafios é a definição clara do regime de colaboração instituído no nosso modelo de estado federado, sem o qual os municípios certamente não conseguirão cumprir as metas estabelecidas no Plano Nacional de Educação e, sobretudo, suprir a enorme demanda que se acumula há anos. 


\section{Eles têm quase tudo ou têm quase nada? O desafio do regime de colaboração}

O modelo de Estado Federal resulta de um pacto ou de uma aliança entre as unidades territoriais, que optaram por compartilhar a soberania entre a União e os entes subnacionais. Pressupõe a busca pela unidade na diversidade, sendo um modelo de Estado vital para países com grandes extensões territoriais, como é o caso brasileiro.

De acordo com Fernando Abrúcio (2003), todo país extenso tem o tema do federalismo batendo à porta, pois isso implica a existência de heterogeneidades que podem dividir e gerar conflitos na nação. Os conflitos podem ser originados não apenas pelas diferenças territoriais, mas também pelas diferenças étnicas, culturais, religiosas, socioeconômicas e até mesmo políticas, que são expressas pela diferença na formação de elites dentro de uma nação.

A configuração de um Estado Federal - ainda segundo Abrúcio (2013) - depende de algumas estruturas, instituições e formas de relações intergovernamentais, para que o objetivo de garantir os direitos de seus pactuantes e o sistema de freios e de contrapesos entre os diferentes níveis de governo possa ser alcançado.

Desse modo, no que compete às estruturas institucionais, é preciso uma carta constitucional escrita, na qual estejam elencados as regras do Estado, as formas de relação entre os entes e os direitos do grupo minoritário; a instituição de uma corte constitucional capaz de julgar as relações entre os níveis de poder e criar uma jurisprudência quanto aos direitos federativos; o estabelecimento do bicameralismo - deputados e senadores e, por fim, a existência de governos descentralizados, com autonomia para produzir suas próprias políticas públicas.

Já no que tange às relações intergovernamentais, o cientista político alerta para o fato de que, embora sejam confundidas com o próprio modelo de Estado, elas existem independentes de um Estado Federal e devem garantir a cooperação entre os entes federados. Abrúcio (2013: 208) elenca cinco formas de relação intergovernamental:

i. fóruns federativos, que permitam o debate e a negociação entre os entes;

ii. mecanismos de indução à descentralização dos níveis locais;

iii. estabelecimento de políticas públicas, que estimulem a cooperação entre os entes federados; 
iv. instituição de uma forma de associativismo territorial, que seja capaz de resolver problemas coletivos em territórios próximos uns aos outros; e, por fim,

v. a quinta forma, associação do tipo horizontal "entre níveis de governo em torno de um tema ou problema, constituindo um mecanismo de advocacy federativo para ser usado na barganha intergovernamental".

Para Daniel Cara (2009: 258), além dessas formas de relação intergovernamentais, reunir uma estrutura institucional bem definida poderá garantir um Estado Federal bem-sucedido. Para o autor, a qualidade de um Estado do tipo federativo está diretamente relacionada à sua capacidade de conjugar autonomia e interdependência entre os entes federados, que é possível, conforme a definição clara de direitos e deveres, e a instituição de arenas e de normas capazes de orientar e arbitrar a atuação dos entes federados.

A apresentação do que seja o modelo de Estado Federal e as condições para que ele se estabeleça são importantes para compreendermos o Estado federativo brasileiro, que também inova com a Constituição Federal de 1988, atribuindo aos municípios o status de ente federado, diferentemente da grande maioria dos Estados Federais. A importância de que as estruturas institucionais e as relações intergovernamentais sejam muito bem postas é a garantia para que os próprios objetivos do Estado Federal sejam garantidos.

O federalismo brasileiro não nasceu de um debate republicano sobre a possibilidade de garantir um Estado central que pudesse reunir e equalizar os interesses de estados autônomos, como ocorreu nos Estados Unidos; nasceu de uma oposição ao Estado absolutista imperial, que centralizava todo o poder político, e o desejo de uma elite oligárquica em trazer para si a autonomia política (Abrúcio, 2003). Nasceu junto com a República, em 1889, sendo instituído na Carta de 1891, mas destaca-se, sobretudo, com a proclamação da Constituição Federal de 1988, tornando-se, dessa forma, um dos Estados mais descentralizados entre os países em desenvolvimento (Souza, 2003; 2005).

Conforme o texto constitucional:

Art. 1․ A República Federativa do Brasil, formada pela união indissolúvel dos Estados e Municípios e do Distrito Federal, constitui-se em Estado democrático de direito [...].

Art. 18. A organização político-administrativa da República Federativa do Brasil compreende a União, os Estados, o Distrito Federal 
e os Municípios, todos autônomos, nos termos desta Constituição (EC no 15/96) (BRASIL, 1988, grifos nossos).

Ainda do texto constitucional, destaca-se o artigo 23, que dispõe sobre a criação de leis complementares para normatizar as formas de cooperação entre os entes federados. Importante ressaltar que, no parágrafo único do artigo supracitado, definiram-se as competências comuns aos entes federados, mas remetendo à definição de regime de cooperação. Desse modo, por exemplo, "proporcionar os meios de acesso à cultura, à educação, à ciência, à tecnologia, à pesquisa e à inovação", conforme o seu inciso $V$, é uma ação que deverá ser realizada cooperativamente entre os entes federados, haja vista ser competência comum de todos. Contudo, quando a Carta de 1988 dispôs o seu artigo 211, no capítulo sobre Educação, ela agregou ao regime de cooperação o regime de colaboração, normatizando, dessa maneira, a forma como os sistemas de ensino dos entes federados deverão organizar-se. Definição específica para os sistemas de ensino, o regime de colaboração incluirá, nesse caso, também a rede privada de ensino.

Para muitos pesquisadores da área das ciências políticas e da educação, a cooperação estabelecida em lei está muito longe de ser alcançada, tendo em vista a não definição clara de suas normas e de como ela deve de fato ser realizada. Para Cibele Franzese (2010), essa falta de clareza da Constituição, além de dificultar a operacionalização das formas de cooperação, cria graves problemas de superposição de ações e accountability ao federalismo brasileiro. Crê-se, desse modo, que a ineficiência do pacto federativo/cooperativo disposto na Constituição tem como causas

a ausência de mecanismos constitucionais ou institucionais que estimulem a cooperação, tornando o sistema altamente competitivo [e] diferentes capacidades de governos subnacionais de implementarem políticas públicas, dadas as enormes dificuldades financeiras, técnicas e de gestão existentes (Souza, 2005: 112).

É importante destacar que as duas razões para a não efetividade da cooperação federativa, mencionadas por Celina Souza (2005), passam pela questão dos municípios. Primeira razão é a não especificação de como o regime colaborativo, ou seja, a cooperação deve se desenvolver entre os entes federados. A segunda tem origem na necessidade de capacitar e induzir as administrações municipais de modo que possam identificar a cooperação intermunicipal e intergovernamental, por exemplo, como uma possibilidade de discussão e resolução de seus problemas locais. Essas duas situações têm deixado os municípios em situação de grandes dificuldades. 
Os municípios são, normalmente, os que recebem os menores recursos, embora sejam responsáveis por grande parte da implementação das políticas públicas no país (Franzese, 2010; Abrúcio, 2013). Das desigualdades técnicas e financeiras entre os entes é que o federalismo cooperativo precisa dar conta. Posto esse desafio, também ficam ao federalismo brasileiro pós-1988 os desafios de reduzir as assimetrias regionais (incluindo as estaduais) e sociais, bem como de provocar o alargamento dos direitos sociais - dentre eles, o direito à Educação. E é nesse sentido que se questiona se o ente federado, definido em 1988, possui quase tudo ou possui quase nada, considerando que a ele foi destinada a execução de grande parte das políticas públicas, ao passo que, dispõe, na maioria das vezes, da menor parcela dos recursos financeiros entre os entes.

Esse desafio que é posto aos municípios estende-se à garantia do direito educacional, considerando-se que a Carta Constitucional de 1988 atribui maior relevância a esse direito, dispondo-Ihe uma seção própria. Além de prever a universalização do Ensino Fundamental, a ampliação e a definição dos recursos a serem gastos com a educação, a gestão democrática e a municipalização do ensino, bem como o projeto descentralizador por meio de relações intergovernamentais, Abrúcio (2013) destaca, também, três aspectos dispostos na Carta que permitem o equilíbrio na execução do direito à educação, quais sejam:

i. a divisão de competências para a execução dos serviços educacionais;

ii. o estabelecimento de ação prioritária para cada ente federado, com a União ditando normas e diretrizes;

iii. o estabelecimento de regime de colaboração.

Observa-se, todavia, que o estabelecimento de ação prioritária para cada ente federado foi definido tão somente com a Emenda Constitucional n. 14 , de 12 de setembro de 1996, que deu nova redação aos §§ 1ㅇ e 2ㅇdo artigo 211 da Constituição de 1988 e ainda incluiu mais dois parágrafos - os $\S \S 3$ e 4으-, que dispõem sobre a atuação prioritária de cada ente federado e, ainda, sobre a importância de que estados e municípios se organizem em forma de colaboração para a universalização do ensino obrigatório.

Quanto ao estabelecimento de ações prioritárias para cada ente federado, a Constituição de 1988 dispõe:

Art. 211. A União, os Estados, o Distrito Federal e os Municípios organizarão em regime de colaboração seus sistemas de ensino. (EC no 14/96 e EC no 53/2006 e EC no 59/2009). 
§ 1‥ A União organizará o sistema federal de ensino e o dos Territórios, financiará as instituições de ensino públicas federais e exercerá, em matéria educacional, função redistributiva e supletiva, de forma a garantir equalização de oportunidades educacionais e padrão mínimo de qualidade do ensino mediante assistência técnica e financeira aos Estados, ao Distrito Federal e aos Municípios.

$\S 2$ 2․ Os Municípios atuarão prioritariamente no Ensino Fundamental e na Educação Infantil.

$\S 3$ 3․ Os Estados e o Distrito Federal atuarão prioritariamente no Ensino Fundamental e Médio.

$\S 4$ ㅇ. Na organização de seus sistemas de ensino, a União, os Estados, o Distrito Federal e os Municípios definirão formas de colaboração, de modo a assegurar a universalização do ensino obrigatório.

§ 5‥ A Educação Básica pública atenderá prioritariamente ao ensino regular (Brasil, 1988, grifos nossos).

Sobre a implementação de um regime de colaboração, conforme observado no artigo 211, Jamil Cury (2010) afirma que a Constituição de 1988, ao estabelecê-lo, optou por um regime normativo e político, descentralizado e plural. Segundo o autor, é importante atentar, diante disso, para a ampliação da arena de participação dos atores políticos que estão nas tomadas de decisão, considerando que a cooperação exige dos entes federativos entendimento mútuo sobre como ela deve operar.

Observa-se, entretanto, que nem a Constituição, nem as leis complementares definiram, até o momento, como esse regime de colaboração deve acontecer efetivamente. Em decorrência disso, observam-se políticas pouco eficazes de acesso e permanência na escola, além da pluralidade de redes/sistemas de ensino com perfil socioeconômico, político e de capacidade técnica e financeira diferentes, seja na relação horizontal ou mesmo na vertical entre os entes federados.

Por fim, para encerrar esta seção, cumpre dizer que quando os municípios brasileiros, na condição de entes federados, tiveram suas prioridades de atendimento e competência educacionais definidas, acabou-se criando, por exemplo, um grande abismo na oferta de Educação Infantil, intensificada com a Emenda Constitucional n.o 59/09, que tornou a pré-escola (4 e 5 anos) como etapa obrigatória de escolarização. Isso porque aos municípios delegou-se a responsabilidade de atender prioritariamente 11 dos 14 anos da Educação Básica definidos como obrigatórios, a despeito, conforme já mencionado, serem os entes que dispõem dos menores recursos orçamentários. 
Diante disso, a formalização clara sobre o regime de colaboração, mais do que uma normatização é a explicitação para que os estados e a União não operem pelo "desejo" de cooperar, mas que assim o façam efetivamente. Entende-se ser essa a saída aos municípios que, com suas altas demandas por atendimento para essa primeira etapa da Educação Básica, têm sido comumente acionados pelos órgãos de defesa da criança e do adolescente para o cumprimento da lei. Essa demanda jurídica em torno da garantia de um direito educacional, tendo em vista o quadro normativo estabelecido desde a Constituição Federal de 1988, bem como as evoluções no campo das políticas públicas para a infância, constitui o tema em destaque na próxima seção.

\section{A judicialização da educação: como se constituiu o processo}

Nos anos de 1980 - período de transição do autoritarismo para a democracia -, o tema do acesso à Justiça, no Estado brasileiro, veio à tona trazendo discussões acerca da garantia dos direitos dos indivíduos e das coletividades, em virtude do abuso de poder de entes estatais ou, então, do não cumprimento de normas constitucionais vinculadas às políticas públicas. A Constituição aqui instaurada no final da década de 1980 estabeleceu o acesso à Justiça como um princípio constitucional e garantiu às instituições jurídicas - tais como a Magistratura, a Defensoria Pública e o Ministério Público (MP) - o reconhecimento como instituições essenciais à Justiça (Motta, 2008).

O fortalecimento das instituições jurídicas, assim como à expansão do direito, com a inserção de agentes jurídicos na esfera pública, é definido nas ciências políticas como o processo de judicialização da política, que se define como

a participação ativa de juízes e tribunais na criação e no reconhecimento de novos direitos, bem como no saneamento de omissões do governo. [...] transposição para o Judiciário de uma parcela dos poderes decisórios típicos do Legislativo e do Executivo, que vem se dando sobretudo a partir de uma publicização do direito, marcada pela ascensão do direito constitucional sobre o direito privado (Casagrande, 2008: 16).

O tema da judicialização é controverso. No que tange à opinião contrária ao processo, encontram-se os representantes do eixo procedimentalista - Tocqueville, Garapon e Habermas. Esse eixo considera que o Judiciário, ao assumir decisões relativas aos poderes de representação - Executivo e Legislativo -, coloca em risco 
os princípios da divisão dos poderes. Diante disso, entende-se que o juiz extrapola suas atividades e passa a legislar e, ainda, a tomar decisões que são do Executivo, quando, por exemplo, determina a realização efetiva de políticas públicas. Desse modo, o princípio da divisão dos poderes pensado por Montesquieu fica fragilizado (Werneck Vianna et alii, 1999; Jasmim, 2005).

Por outro lado, aqueles que expressam uma opinião mais positiva em relação ao processo, representantes do eixo substancialista - Cappelletti e Dworkin -, entendem que o Judiciário não estaria assumindo as funções dos demais poderes, tendo em vista que Judiciário, Executivo e Legislativo atuam em sentido complementar, em prol da concretização dos direitos e das políticas que os próprios poderes propuseram. Aqueles de opinião positiva sobre o processo defendem ainda que, mesmo que ocorra a sobreposição de funções, isso decorrerá apenas em função da inércia de um dos poderes representativos. Logo, a atuação do Judiciário tornar-se-ia positiva, pois estaria garantindo o exercício da cidadania (Werneck Vianna \& Burgos, 2003; Casagrande, 2008; Eisenberg, 2003).

Entre os dois eixos resumidamente apresentados, encontra-se um ponto de convergência, dado que ambos entendem que o Poder Judiciário tem figurado nas sociedades democráticas como instituição estratégica para a garantia da autonomia individual e cidadã. Observa-se, contudo, que além do Poder Judiciário, no Brasil, encontra-se a expressiva atuação do Ministério Público, instituição que desde a Constituição de 1988, teve redefinidas suas funções perante o Estado, tendo como premissa a defesa de pessoas em seu caráter individual (desde que haja interesse social), de grupo de pessoas e de toda sociedade, tão logo seja identificado a inconstitucionalidade de um direito (Mazzilli, 2007). A redefinição das funções do Ministério Público no Brasil corroborou, de acordo com pesquisa realizada por Werneck Vianna (2003), para a definição de um dos atores mais presentes na proteção dos interesses coletivos e difusos, na provocação do Poder Judiciário, na realização de inquéritos civis e, ainda, na realização de acordos entre as partes, seja no âmbito judicial ou extrajudicial, logo, na garantia de direitos.

Mais especificamente, interessa-nos entender aqui como esse processo alcança a esfera educacional. Quando falamos de judicialização da Educação, falamos da intervenção jurídica para a garantia de direitos educacionais que não estão sendo atendidos pelo Poder Executivo e/ou Legislativo, que, nesse caso, agem inconstitucionalmente. Dessa forma, a judicialização da Educação, segundo Cury e Ferreira,

[...] ocorre quando aspectos relacionados ao direito à educação passam a ser objetos de análise e julgamento pelo Poder Judiciá- 
rio. Em outros termos, a educação, condição para a formação do homem, é tarefa fundamental do Estado, é um dos deveres primordiais, sendo que, se não o cumprir, ou o fizer de maneira ilícita, pode ser responsabilizado (Muniz, 2002: 211).

Esta responsabilização com a intervenção do Poder Judiciário consolida o processo de judicialização da educação (Cury \& Ferreira, 2009: 8-9).

Convém dizer que a educação passou a ser objeto de análise e julgamento do Judiciário considerando que o próprio legislador da Carta Constitucional de 1988, ao estabelecer inúmeros direitos dos cidadãos, estabeleceu, ainda, os remédios jurídicos para a sua proteção e garantia. Diante disso, no artigo 208 da Constituição, a educação é definida como direito público subjetivo, que é aquele que o cidadão poderá reivindicar, quando não estiver sendo garantido. Isso se confirma pelo detalhamento do seu parágrafo 2ㅇ: "o não oferecimento do ensino obrigatório pelo poder público, ou sua oferta irregular, importa responsabilidade de autoridade competente" (Brasil, 1988).

Dentre as instituições possíveis de exigir a garantia dos direitos está o Ministério Público, que, conforme apresentamos, em caso de inobservância do direito ao acesso à educação, poderá ser acionado pela família, e reivindicar tal direito junto ao poder competente.

Importa dizer, contudo, que não apenas o Ministério Público pode fazer essa reivindicação, mas também os Conselhos Tutelares, que são órgãos permanentes, autônomos e não jurisdicionais, que possuem representatividade e a função de garantir os direitos das crianças e dos adolescentes, conforme definido no artigo 131 do Estatuto da Criança e do Adolescente (ECA). Como órgão mais próximo das comunidades, os conselhos têm sido mesmo a primeira instituição de busca de ajuda das famílias que reivindicam algum direito. Como são investidos do poder de requisitar serviços, quando recebem a demanda, encaminham suas requisições ao poder público responsável; quando não solucionado o problema, comumente o encaminham para as instituições jurídicas.

Para finalizar esta seção, ressalta-se que, se a judicialização da educação significar entre nós o meio de garantir o acesso à educação, de modo que o Judiciário atue em substituição ao Executivo ao determinar a realização de matrículas, a criação de vagas, a contratação de professores, dentre outras ações, o objetivo de se construir uma cidadania ativa com cidadãos livres estará fadada ao fracasso. Contudo, torna-se inevitável falar de seu aspecto positivo, tendo em vista que vivemos num cenário de vida associativa ainda pouco expressiva, em que a efetividade dos direitos de 
interesses comuns é reduzida à representação definida nas eleições. Além disso, a sua ocorrência serve como um sinal de alerta de que é necessário repensar as políticas públicas na área, bem como a necessidade de definir o regime de colaboração, que entendemos ser essencial para que os municípios atuem na garantia do direito à Educação Infantil.

A seguir, na última seção, apresenta-se o processo de judicialização da Educação Infantil no município de Juiz de Fora-MG, que foi analisado a partir da atuação do Ministério Público e dos Conselhos Tutelares.

\section{A judicialização da Educação Infantil: o caso de Juiz de Fora (MG)}

A pesquisa realizada no município de Juiz de Fora teve como motivação os dados levantados relativos a acesso, permanência e qualidade da educação referente a um período de 15 anos (1996 a 2011), com fins de identificar a atuação do Ministério Público na garantia do direito à educação no município. Essa pesquisa verificou que havia em Juiz de Fora uma demanda muito elevada por vagas para a Educação Infantil, em especial para a subetapa de creche - em torno de duas mil vagas. Ademais, verificou-se a atuação preponderante dos Conselhos Tutelares, a despeito da hipótese de que o Ministério Público seria o ator mais judicializante, como apontava a bibliografia sobre o tema (Casagrande, 2008; Werneck Vianna, 1999).

Por se tratar de demanda registrada não apenas no município de Juiz de Fora, mas em todo o Brasil (Damasco, 2008; Barreto, 2003; Pompeu, 2005), a pesquisa que será detalhada agora, buscou analisar a atuação do Ministério Público - bem como dos Conselhos Tutelares - na garantia do direito à Educação Infantil, considerando que, além da grande demanda persistente na cidade, os municípios têm como norte o cumprimento das metas do Plano Nacional de Educação (2014-2024) para a primeira etapa da Educação Básica, conforme já exposto aqui.

Para a realização desta pesquisa, coletaram-se dados em 37 livros de registros de sentenças arquivados na secretaria da Vara da Infância e Juventude (VIJ) da Comarca de Juiz de Fora, compreendendo o período de 1ํo de janeiro de 2012 a 30 de agosto de 2014, e que tornou possível identificar ações iniciadas no Ministério Público ou os posicionamentos dos promotores, quando a causa da lide era a garantia do direito à Educação Infantil. Para complementar essa pesquisa, foram realizadas entrevistas semiestruturadas com o promotor titular da Vara da Infância e Juventude, com o promotor responsável pela área civil da Infância e Juventude e, por fim, uma entrevista informal com uma oficial de justiça que atuava diretamente com o promotor titular. 
A pesquisa prosseguiu para a Secretaria de Educação, onde foram realizadas entrevistas com gestores do Departamento de Educação Infantil, supervisoras de Escolas Públicas de Educação Infantil e de Creches Públicas, com o gestor responsável pela rede física e implementação do Proinfância, e, por fim, com dois secretários de educação, o que estava ocupando a cadeira no momento da pesquisa e a secretária da gestão anterior. Além dessas entrevistas, dados relativos às vagas da Educação Infantil foram obtidos junto aos Departamentos de Educação Infantil e ao Departamento de Inclusão e Atenção ao Educando.

Para enriquecer a análise, os Conselhos Tutelares do município também foram objeto da pesquisa. Ao todo, foram entrevistados sete dos doze conselheiros tutelares atuantes naquele período, sendo que eles se encontravam distribuídos na sede dos três conselhos presentes na cidade. Nos conselhos, além das entrevistas, coletaram-se dados nos relatórios estatísticos de atendimento que são ali elaborados e que deveriam ser entregues semestralmente ao Conselho Municipal de Defesa da Criança e do Adolescente. Ocorre, porém, que nem todos os relatórios haviam sido feitos, pois os conselhos passavam por limitações, que iam desde a falta de conselheiros para compor o quadro de cinco profissionais até a falta de material de uso diário.

Por fim, foi realizada entrevista com o vereador e presidente da Comissão Permanente de Defesa da Criança e do Adolescente da Câmara Municipal, Jucélio Maria. Essa entrevista se justifica pelo fato de o vereador ter sido responsável por convocar, de maneira inédita no tocante ao tema, uma audiência pública em 2013 para tratar da falta de vagas nas creches públicas de Juiz de Fora. Esse momento foi considerado bastante relevante, pois, além de o Legislativo configurar como um novo ator na luta pela garantia dos direitos educacionais das crianças de 0 a 5 anos, a audiência contou com a participação de pais e mães, dos Conselhos Tutelares e da Secretaria de Educação de Juiz de Fora, apresentando o seu Plano de Expansão de Atendimento da Educação Infantil.

O sistema municipal de ensino é composto por escolas de Educação Infantil; escolas de Educação Infantil e Ensino Fundamental; creches públicas e creches conveniadas. Até o ano de 2014, existiam no município apenas seis escolas exclusivas para a pré-escola, mas com a meta de universalizar o atendimento até 2016, em 2015 a Secretaria de Educação passou a contar com doze instituições.

As creches públicas de Juiz de Fora estão, desde 2009, sob a responsabilidade da Associação Municipal de Apoio Comunitário, no que compete à execução das atividades, permanecendo sob a responsabilidade da Secretaria de Educação a 
orientação pedagógica e o repasse de verbas públicas. Observa-se, contudo, que as creches, para atender a determinação da LDB, foram integradas à Secretaria de Educação apenas no ano de 2008, em razão da dificuldade de repassar recursos da assistência social para a Secretaria de Educação. Com isso, o vínculo empregatício dos funcionários da Associação Municipal de Apoio Comunitário, que já eram responsáveis pelas creches, e o interesse da mesma em manter o serviço sob sua custódia foram ratificados (Zanetti, 2009). No tocante a este tema, não é possível desconsiderar que a oferta educacional via Associação Municipal traz certos prejuízos, como ausência de um plano de carreira e remunerações, bem como a instabilidade dos funcionários que nela atuam, indo na contramão das reivindicações feitas para esta etapa da educação básica.

Ao todo, em 2014, a Secretaria contava com 21 creches públicas geridas pela Associação Municipal de Apoio Comunitário, e 23 conveniadas, das quais quatro creches conveniadas na modalidade "cessão de professores"; e 19 na modalidade "repasse de verbas". Além disso, conforme destaca Castro (2013), algumas escolas municipais que atendem crianças de 4 e 5 anos também estavam oferecendo turmas de três anos.

1. A demanda por vagas é definida conforme a procura na Secretaria de Educação e o cadastro nos Conselhos Regionais de Assistência Social (Cras). Cumpre dizer que, segundo depoimento de conselheira tutelar entrevistada, Maria de Lourdes, a demanda pode ser muito maior, já que as famílias quando chegam aos Cras são orientadas a se registrarem em outro programa para obtenção de outros benefícios, como o Vale Gás. Tal medida é feita, segundo a conselheira, para não impactar o índice da demanda, já que não há vagas nas creches em número suficiente.
Sobre a demanda para as duas subetapas da Educação Infantil ${ }^{1}$, tanto as supervisoras como a chefe do Departamento de Educação Infantil não souberam precisar durante a entrevista demanda específica para a pré-escola, pois, segundo informaram, além de ser pequena, oscilava bastante, já que as vagas existiam, embora elas às vezes não atendessem à necessidade ou à escolha dos pais. Tanto a supervisora como a chefe do departamento e o secretário de Educação em exercício afirmaram a universalização da pré-escola no município.

No que diz respeito à demanda por vagas em creches, contudo, observou-se que a demanda ainda é bastante elevada. Em outubro de 2014 a rede apresentava o seguinte quadro de atendimento:

\section{TABELA 1}

ATENDIMENTO E DEMANDA POR CRECHES

NO MUNICÍPIO DE JUIZ DE FORA EM 2014

\begin{tabular}{|c|c|c|c|}
\hline Vagas em creches públicas & Vagas em creches conveniadas & Total de vagas em creches & Demanda reprimida \\
\hline 2.558 & 1.251 & 3.809 & 1.335 \\
\hline
\end{tabular}

Ao se considerar, portanto, a pesquisa concluída em 2011, identificou-se que em Juiz de Fora a demanda por vagas em creches permanecia inalterada. Apesar disso, 
a pesquisa de doutorado concluída em 2015 possibilitou um novo olhar sobre o tema, visto que o crescimento das reivindicações jurídicas ou requisições dos Conselhos Tutelares em torno do direito não aumentaram. Ao que tudo indica, em Juiz de Fora, o processo de judicialização passou por uma redefinição, tendo em vista a atuação dos órgãos de defesa da criança e do adolescente.

A pesquisa identificou, especificamente, uma fragilidade muito grande no que viria a se chamar "rede de proteção social da criança e do adolescente". Observou-se que a rede não se constitui enquanto tal, pois os conselhos, bem como a Promotoria Pública, não se reconhecem como órgãos capazes de garantir a defesa dos direitos que estávamos analisando - acesso à Educação Infantil. Observou-se que os Conselhos Tutelares reconhecem bem os problemas relacionados à falta de vagas para Educação Infantil, em destaque feito por todos, das vagas em creches. Eles reconhecem, ainda que apresentem pequenas confusões, as metas do Plano Nacional de Educação para atendimento nessa etapa, identificando ações realizadas para ampliação das vagas no município, dentre as quais estão: o aumento do número de convênios com instituições particulares de ensino, a reestruturação dos espaços físicos já existentes e a construção de novas unidades de ensino. Assim, todos citaram as obras do Proinfância do governo federal em parceria com os municípios, mas sem, necessariamente, reconhecê-las como política colaborativa entre os dois entes federados. A percepção mais geral é de que são obras iniciadas na gestão 2009-2012 e que foram entregues no final o atual mandato, entre 2013-2016, sendo que houve alternância de partido à frente do governo municipal.

No que compete às obras do Proinfância, cabe informar que, até 2014, o município foi beneficiado com dez projetos, criando a expectativa de ampliação de mais de 800 novas vagas em toda a rede. Entretanto, muitas obras estão em atraso devido a inúmeras razões como: a geografia do próprio município, que não contribui para a adequação do projeto, conforme rege a política do governo federal; a decretação de falência das empresas contratadas para construir as unidades de ensino; os problemas na documentação dos terrenos destinados à obra; os problemas de interesse dos bairros que receberiam unidades Proinfância e, por que não, ao que tudo indica, o interesse político, já que, entre as unidades previstas para inauguração no final do ano de 2014, foram entregues no final do segundo semestre de 2015 (Mattos, 2014).

No que respeita aos Conselhos Tutelares, identificou-se, ainda, uma grande queixa em relação à forma como são tratados pelo poder público, reconhecidos pelo Judiciário e o alcance que suas ações têm alcançado. Segundo depoimentos de conselheiros, além de não terem nenhum contato com o Ministério Público, seus 
pedidos têm sido engavetados, o que tem contribuído para um desencorajamento de atuação no tema, não apenas em relação a eles próprios, mas esmorecendo as famílias de investirem em um pedido feito através do Conselho Tutelar, já que não têm obtido retorno ou não têm sido ouvidos pelos órgãos competentes com os quais poderiam atuar em parceria. Isso fica claro nos depoimentos reproduzidos a seguir:

O sistema de garantia e de direitos está completamente ilhado, um aqui e outro ali. [...] Outros Conselhos Tutelares que têm uma atuação de parceria com esses órgãos com liberdade de ir ao Ministério Público, de ir ao gabinete da juíza, são recebidos enquanto autoridades constituídas que são e aí o trabalho deslancha, a coisa anda mais próxima. E isso a gente ainda não conseguiu aqui em Juiz de Fora (CT - Delfina, 2014).

$[\ldots]$

"Se você judicializar eu vou engavetar". [...] Eu ouvi promotor falar na minha cara, "o que a senhora judicializar eu engaveto". Eu cobrei da juíza! (CT - Maria de Lourdes, 2014).

Já no que compete ao Ministério Público, observou-se, do mesmo modo, uma descrença em relação ao trabalho dos Conselhos Tutelares. Em princípio, o questionamento é que eles não reconhecem os limites de atuação da instituição e que também estão bastante desmotivados a atuarem, tendo em vista o processo de escolha de novos conselheiros realizado em outubro de 2013 e que se encontrava judicializado, por questionamentos quanto à publicação do edital. No mais, observou-se ainda que a promotoria tem atuado sobremaneira nos casos infracionais de crianças e adolescentes; que não há uma compreensão clara das políticas educacionais, indicando até mesmo a atuação das creches como atividade mais de assistência do que propriamente educacional.

A situação que nos chamou mais a atenção, entretanto, está relacionada ao reconhecimento de que o Poder Executivo tem feito todas as ações possíveis para que o problema da grande demanda por vagas em creches e pré-escolas no município seja resolvido. Isso se justifica, segundo os atores pesquisados, porque o município não dispõe dos recursos necessários para a ampliação das vagas, o que nos remete à discussão sobre a importância da definição clara do regime de colaboração entre os entes federados.

Desse modo, justifica-se o depoimento dos integrantes dos Conselhos Tutelares, ao afirmarem que os pedidos têm sido engavetados. Na própria entrevista com o promotor, ou mesmo com os secretários de Educação, ficou claro que, apesar 
de a Secretaria de Educação comumente ser chamada a prestar contas sobre o problema e, até mesmo, ser chamada a cumprir a determinação de matricular crianças nas unidades de ensino, o Poder Judiciário e o Ministério Público têm como compreensão comum que aquilo que é possível ser feito, está sendo feito. Aqui chegamos a um ponto importante para reflexão: qual o limite de atuação dos órgãos da Justiça e de defesa e reivindicação dos direitos sociais (e nesse caso, público e subjetivo), como o Ministério Público e os Conselhos Tutelares? Como atuar diante da ausência de recursos do município e do crescimento de uma demanda reprimida? Estaríamos em Juiz de Fora sem alternativa para o problema de ordem pública/social?

Diante desse cenário, entendemos que, em Juiz de Fora, estaria havendo, apesar da crescente demanda por um direito educacional, não mais um processo contínuo de judicialização da Educação Infantil, mas uma "desjudicialização", tendo em vista que as instituições que poderiam atuar em prol da exigibilidade desse direito não mais estariam fazendo isso. Em outros termos, se a judicialização se define pela atuação do Poder Judiciário e, em especial, no Brasil, pelo Ministério Público, para a exigibilidade de direitos definidos constitucionalmente, acionando Poder Executivo pelo cumprimento da lei; e se em Juiz de Fora essa relação se estagnou, tendo em vista que o Judiciário e os demais órgãos têm "compreendido" os argumentos do poder público municipal a respeito da ausência de recursos e de medidas emergenciais tomadas para sanar o problema da demanda, não mais estaria ocorrendo a judicialização no município, mas aquilo que definimos desjudicialização, combinada com o retorno da política para a "sua casa", ou seja, para o Poder Legislativo.

Esse "elemento" novo que se apresentou na "briga" pela garantia do direito à Educação Infantil chegou a partir da atuação do ex-vereador Jucélio Maria (PSB), que convocou audiência pública para discutir a inexistência de vagas no município, levando diferentes grupos para discutirem o problema, incluindo as mães de crianças desassistidas para relatarem o problema ocasionado pela falta de vagas. Segundo entrevista realizada com o ex-vereador, essa audiência foi proposta a partir do reconhecimento dos números da demanda do município, das metas estipuladas pelo Plano Nacional de Educação e, ainda, dos inúmeros pedidos que ele e os demais vereadores recebem diariamente em seus gabinetes de mães e pais solicitando vagas para seus filhos.

Alguns resultados positivos foram obtidos a partir dessa audiência pública. O primeiro deles foi a apresentação de um Plano de Expansão das escolas e vagas de Educação Infantil da Prefeitura Municipal e, também, a distribuição de vagas nas 
escolas conveniadas a partir da classificação da criança no Cadastro Único dos Centros de Referência de Assistência Social. Para o ex-vereador, tal medida veio moralizar o atendimento, uma vez que as crianças passariam a ser atendidas pelo critério de vulnerabilidade social e não pela intervenção política de algum colega da casa legislativa.

\section{Considerações finais}

Ao tomar por base a experiência identificada no município mineiro, é possível dizer - respondendo à questão inicial que nos propusemos - que a atuação de Promotorias da Infância e Juventude, bem como dos Conselhos Tutelares, tem encontrado limites para garantir efetivamente o direito ao acesso à Educação Infantil. Além dos problemas de representatividade e de reconhecimento institucional que foram brevemente mencionados, a inatividade dos órgãos de proteção da criança e do adolescente observada, parte de uma justificativa do Poder Executivo de que tudo o que é possível ser feito para ampliar o atendimento tem sido realizado. Isso é feito acatando decisões judiciais de matricular crianças como excedentes nas escolas, o que contribui para a queda na qualidade do atendimento que é prestado e, até mesmo, coloca em risco não só as crianças, mas também o trabalho dos profissionais que com elas atuam. Essa justificativa apresentada ao Poder Judiciário e ao Ministério Público tem chegado aos Conselhos Tutelares como um freio às suas requisições, já que sabem do seu provável engavetamento.

Desse modo, num primeiro momento, nos restaria a efetividade de um regime de colaboração, que, se bem definido, em tese, colocaria os municípios em condições reais de atender às demandas para a Educação Infantil. Sendo eles responsáveis por atender, prioritariamente, 11 dos 14 anos de escolaridade obrigatória e mais três anos da primeira subetapa da Educação Infantil (as creches), a falta de colaboração técnica e financeira entre estado e União, prevista na Constituição, coloca os municípios em uma situação bastante complicada, tornando improvável o cumprimento das metas do Plano Nacional de Educação, e na condição de educar pela via da judicialização, sem, necessariamente, ofertar uma educação de qualidade.

Contudo, e por fim, não podemos deixar de mencionar a aprovação do Projeto de Emenda Constitucional n.o 55, que institui o novo regime fiscal, que vigorará nos próximos 20 anos, limitando os investimentos em educação. O cenário que se vislumbra com tal projeto para a primeira etapa da educação básica (mas também para as posteriores) é: ampliação da demanda reprimida; aumento da demanda judicial para garantia do direito; municípios ainda mais descapitalizados para am- 
pliação das vagas; União e estados sem recursos para a contrapartida prevista em regime de colaboração financeira e técnica; e as crianças e adolescentes tendo seus direitos não realizados e todas as demais mazelas sociais que em longo prazo podem decorrer daí.

\section{Referências}

ABRÚCIO, F. L. Federalismo e educação no Brasil: trajetória recente e principais desafios. In: CRUZ, Priscila; BARBOSA, Helia (Orgs.). Justiça pela qualidade na educação, v. 1, p. 205-220. São Paulo: Saraiva, 2013.

Reforma política e federalismo: desafios para a democratização brasileira. In: BENEVIDES, Maria Victoria; KERCHE, Fábio; VANNUCHI, Paulo (Orgs.). Reforma política e cidadania, p. 225-265. São Paulo: Editora Fundação Perseu Abramo, 2003.

ARIÈS, Philippe. História social da criança e da família. 2. ed. São Paulo: LTC, 1986.

BARRETO, A. M. R. F. A educação infantil no contexto das políticas Públicas. Revista Brasileira de Educação, n. 24, p. 53-65, Set./Dez. 2003.

BRASIL. Lei n. 13.005, de 25 de julho de 2014. Aprova o Plano Nacional de Educação (PNE) e dá outras providências. Disponível em: <http://www.planalto.gov.br/ ccivil_03/_Ato2011-2014/2014/Lei/L13005.htm>. Acesso em: 03 Jan. 2015.

Lei $n$. - 12.796, de 04 de abril de 2013. Altera a Lei 9.394 [...] para dispor sobre a formação de profissionais da educação e dar outras providências. Disponível em: <http://www.planalto.gov.br/ccivil_03/_Ato2011-2014/2013/Lei/L12796. htm>. Acesso em: 06 Abr. 2013.

Lei n. 11.494, de 20 de junho de 2007. Regulamenta o Fundo de Manutenção e Desenvolvimento da Educação Básica e de Valorização dos Profissionais da Educação (Fundeb) [...]. Disponível em: <http://www.planalto.gov.br/ccivil_03/_ ato2007-2010/2007/Lei/L11494.htm>. Acesso em: 06 Abr. 2013.

Lei n. 10.172, de 9 de janeiro de 2001. Aprova o Plano Nacional de Educação e dá outras providências. Disponível em: <http://www.planalto.gov.br/ccivil_03/ leis/leis_2001/I10172.htm>. Acesso em: 25 Mar. 2013.

Lei n.o 8.069, de 13 de julho de 1990. Dispõe sobre o Estatuto da Criança e do Adolescente e dá outras providências. Disponível em: <http://www.planalto.gov. br/ccivil/LEIS/I8069.htm>. Acesso em: 28 Mar. 2013. 
- Constituição da República Federativa do Brasil de 1988. Disponível em: <http://www.planalto.gov.br/ccivil_03/constituicao/constituicaocompilado.htm>. Acesso em: 17 Mar. 2013.

CARA, Daniel. Municípios no pacto federativo: fragilidades sobrepostas. Revista Retratos da Escola, v. 6, n. 10, p. 255-273, Jan./Jun. 2009.

CASAGRANDE, C. Ministério Público e a judicialização da política: estudos de caso. Porto Alegre: Sérgio Antônio Fabris Editor, 2008.

CASTRO, Fabiana Gonçalves Dias de. O atendimento às crianças de três anos nas escolas da rede municipal de ensino de Juiz de Fora: um desafio à gestão da qualidade na educação infantil. Dissertação (Mestrado em Gestão e Avaliação da Educação Pública) - Universidade Federal de Juiz de Fora, Juiz de Fora, Minas Gerais, 2013.

CERISARA, Ana Beatriz. O referencial curricular nacional para a Educação Infantil no contexto das reformas. Educação e Sociedade, v. 23, n. 80, p. 326-345, Set. 2002. Disponível em: <http://www.scielo.br/pdf/es/v23n80/12935.pdf>. Acesso em: 15 Jan. 2013.

CORREA, Patrícia Santiago de Medeiros. A efetivação do direito à creche - a judicialização de uma política de gênero. Anais do XIX Encontro Nacional do Conpedi. Fortaleza, 2010. Disponível em: <http://150.162.138.7/documents/277>. Acesso em: 10 Jan. 2015.

CURY, C.R. A questão federativa e a educação escolar. In: OLIVEIRA, R. P; SANTANA, W. (Orgs.). Educação e federalismo no Brasil: combater as desigualdades, garantir a diversidade. Brasília: Unesco, 2010.

CURY, C. R. J.; FERREIRA, L. A. M. A judicialização da educação. Revista CEJ, v. 1, p. 32-45, 2009.

DAMASCO, Denise Gisele de Britto. O direito à educação: atuação das Promotorias de Justiça e de Defesa do Ministério Público do Distrito Federal e Territórios, entre 2001 e 2007. Dissertação (Mestrado em Educação) - Faculdade de Educação da Universidade de Brasília. Brasília, 2008.

DOURADO, Luiz Fernandes. Sistema Nacional de Educação, federalismo e os obstáculos ao direito à educação básica. Educação e Sociedade, v. 34, n. 124, p. 761-785, Jul./Set. 2013.

EISENBERG, J. Pragmatismo, direito reflexivo e judicialização da política. In: WERNECK VIANNA (Org.). A democracia e os três poderes no Brasil, p. 43-62. Belo Horizonte; Rio de Janeiro: Editora UFMG; Iuperj; Faperj, 2003. 
FRANZESE, Cibele. Federalismo cooperativo no Brasil: da Constituição de 1988 aos sistemas de políticas públicas. Tese (Doutorado) - Escola de Administração de Empresas de São Paulo e Fundação Getúlio Vargas, São Paulo, 2010.

FREITAS, Marcos César. História da infância no pensamento social brasileiro. Ou, fugindo de Gilberto Freyre pelas mãos de Mário de Andrade. In: FREITAS, M. C. (Org.). História social da infância brasileira. 3. ed. São Paulo: Cortez, 2001.

GAYOTTO, Maria Leonor Cunha et alii. Creches: desafios e contradições da criação da criança pequena. São Paulo: Ícone, 1992.

INSTITUTO NACIONAL DE ESTUDOS E PESQUISAS EDUCACIONAIS ANÍSIO TEIXEIRA (Inep). Sinopse do professor, 2009, atualizado em: 17 Dez. 2012. Disponível em: <http://portal.inep.gov.br/basica-censo-escolar-sinopse-sinopse>. Acesso em: 04 Abr. 2013.

JASMIM, M. G. Alexis de Tocqueville: a historiografia como ciência da política. 2. ed. Belo Horizonte; Rio de Janeiro: Editora UFMG; Iuperj, 2005.

KRAMER. Sônia. As crianças de 0 a 6 anos nas políticas educacionais no Brasil: Educação infantil e/é fundamental. Educação e Sociedade, v. 27, n. 96, p. 797-818, Out. 2006. Disponível em: <http://www.scielo.br/scielo.php?script=sci_arttext\&pi$d=S 0101-73302006000300009 \&$ lng=pt\&nrm=iso\&tlng=pt $>$. Acesso em: 12 Jan. 2013.

- Pesquisa Infância e educação: um encontro com Walter Benjamin. KRAMER, Sônia; LEITE, Maria Isabel (Orgs.). Infâncias: fios e desafios da pesquisa. "Série Prática Pedagógica". Campinas (SP): Papirus, 1996.

KRAMER, Sônia; CORSINO, Patrícia; NUNES, Maria Fernanda Rezende. Políticas públicas municipais de educação Infantil: um balanço da década. Anais da XXXIV Reunião Anual da Anped. Natal, 2011.

KUHLMANN JR., Moysés. Infância e educação infantil: uma abordagem histórica. Porto Alegre: Mediação, 2004.

MATTOS, Clarice da Silva. A implementação do Proinfância em Juiz de Fora e seus desdobramentos. Dissertação (Mestrado em Gestão e Avaliação da Educação Pública), Universidade Federal de Juiz de Fora, Juiz de Fora (MG), 2014.

MAZZILLI, H. N. O acesso à Justiça e o Ministério Público. 5. ed. São Paulo: Saraiva, 2007. 
MOTTA, L. E. Acesso à justiça, cidadania e judicialização no Brasil. Disponível em: <http://www.achegas.net/numero/36/eduardo_36.pde>. Acesso em: 18 Maio 2008

PASSETTI, Edson. Crianças carentes e políticas públicas. In: PRIORE, Mary Del (Org.). História das crianças no Brasil. 4 ed. São Paulo: Contexto, 2004.

PINTO, José Marcelino de Rezende. Perfil da educação infantil no Brasil: indicadores de acesso e condições de oferta. In: BRASIL/MEC/SEB. Política de Educação Infantil no Brasil: Relatório de avaliação, p. 121-168. Brasília: MEC/SEB; Unesco, 2009.

PINTO, Manuel. A infância como construção social. PINTO, Manuel; SARMENTO, Manuel Jacinto (Coords.). As crianças: contextos e identidades. "Coleção infans - Centro de estudos da criança". Braga (PT): Universidade do Minho, 1997.

POMPEU, Gina Vidal Marcílio. Direito à educação: controle social e exigibilidade judicial. Rio de Janeiro; São Paulo; Fortaleza: ABC, 2005.

ROSEMBERG, Fúlvia. Organizações multilaterais, Estado e políticas de educação infantil. Cadernos de Pesquisa, n. 115, p. 25-63, Mar. 2002. Disponível em: <http:// www.scielo.br/scielo.php?script=sci_arttext\&pid=S0100-15742002000100002\&lng $=e n \& n r m=i s o \& t \operatorname{lng}=p t>$. Acesso em: 21 Jan. 2013

Expansão da educação infantil e processos de exclusão. Cadernos de Pesquisa, n. 107, p. 7-40, Jul. 1999. Disponível em: <http://www.scielo.br/scielo.php?script=sci_arttext\&pid=S0100-15741999000200001\&lng=en\&nrm=iso\&tlng=pt $>$. Acesso em: 20 Jan. 2013.

SHERÉR, René. Infantis: Charles Fourier e a infância para além das crianças. Belo Horizonte: Autêntica, 2009.

SILVEIRA, A. A. D. A exigibilidade do direito à educação básica pelo Sistema de Justiça: uma análise da produção brasileira do conhecimento. Revista Brasileira de Política e Administração da Educação (RBPAE), v. 24, n. 3, p. 537-55, 2008.

SOUZA, Celina. Federalismo, desenho constitucional e instituições federativas no Brasil pós-1988. Revista Sociologia Política, v. 24, p. 105-121, Jun. 2005.

Federalismo e conflitos distributivos: disputa dos estados por recursos orçamentários federais. Dados - Revista de Ciências Sociais, v. 4, n. 2, p. 345-384, 2003.

VIEIRA, K. M. Efetivação do direito fundamental à vaga em creche. Monografia (Bacharelado em Ciências Sociais e Jurídicas) - Centro de Ciências Sociais e Jurídicas da Universidade do Vale do Itajaí, São José (SC), Jun. 2008. 
VIEIRA, Lívia Maria Fraga. Educação da criança pequena na legislação educacional brasileira no século XX: abordagem histórica no estado de Minas Gerais. Anais da XXX Reunião Anual da Anped. Caxambu, 2007. Disponível em: <http://www.anped. org.br/reunioes/30ra/trabalhos/GT07-3692--Int.pdf>. Acesso em: 10 Jan. 2013.

WERNECK VIANNA, L; BURGOS, M. Revolução processual do direito e democracia progressiva. In: WERNECK VIANNA (Org.). A democracia e os três poderes no Brasil. Belo Horizonte; Rio de Janeiro: Editora UFMG; Iuperj; Faperj, 2003.

WERNECK VIANNA L; CARVALHO, M. A. R. de; MELO, M. P. C.; BURGOS, M. B. A judicialização da política e das relações sociais no Brasil. Rio de Janeiro: Revan, 1999.

ZANETTI, A. Creches no sistema de ensino de Juiz de Fora: velhos dilemas e novas perspectivas. XXIV Simpósio Brasileiro III Congresso Interamericano de Política e Administração da Educação, Vitória, 2009. Cadernos Anpae, 2009. 